\title{
A Conceptual Review On Strategic Human Resources Management And Planning In Non Profit Motive Organization
}

\author{
Gyanendra Bikram Shah, MPhil \\ Faculty, Nepal Commerce Campus, TU \\ gshahdp1@gmail.com
}

\begin{abstract}
The nonprofit and public sectors are facing significant numbers of impending retirements from the traditionalists and baby boomers in their workforces. In an effort to retain the knowledge base of an agency or to better serve its clients, some organizations have developed creative ways to encourage retirement-eligible employees to remain on the job. Public and nonprofit organizations are driven by the knowledge and skills their employees possess. It is shortsighted for elected officials, board members, funders, executives, and other agency leaders to dismiss the importance of SHRM. As important, organizations must reinforce the importance of human capital and the contribution that knowledge management makes to the effective delivery of services.
\end{abstract}

Keywords: Non Profit Motive Organization, Strategic Human Resource, HR Planning, Effectiveness

\section{Introduction}

Non-profit organization (NPO) is one which is not driven by profit or surplus after operating expenses but by dedication to a given cause that is the target of all income beyond what it takes to run the organization. Associations, charities, cooperatives, and other voluntary organizations formed to further cultural, educational, religious, professional, or public service objectives. Their startup funding is provided by their members, trustees, or others who do not expect repayment, and who do not share in the organization's profits or losses which are retained or absorbed. Approved, incorporated, or registered NPOs are usually granted tax exemptions, and contributions to them are often tax deductible. Most non-governmental organizations (NGOs) are NPOs. The funding can be an issue for non-profits as they often rely on external sources, such as donations. Scrupulous 
accounting, transparency and accountability are essential to continuation of operations, as mismanaged or misdirected funds could result in the loss of funding from both public and private sources and loss of status. The state and local governments across the country are facing severe revenue shortfalls and are planning to eliminate funding for many programs and services. The strategies they are using to balance their budgets are to reduce or eliminate services, lay off employees and increase and institute user fees for many of the services that will remain. Individuals remaining after the layoffs need to possess the requisite knowledge, skills, abilities, and other characteristics (KSAOCs) to keep the programs and services operating effectively. This chapter discusses SHRM, the changing role of HRM, and human resources planning and illustrates the importance of all these concerns to organizational vitality and success.

\section{Strategic Human Resources Management}

Strategic planning is the process that enables public organizations to guide their future activities and the use of their available resources. It assists elected officials, funders, foundations, citizens, business partners, and public administrators in determining organizational purposes and objectives. The strategic planning process permits the external forces that affect the organization and the people in it to be identified. These forces may include workforce patterns, economic conditions, competition, regulation, social values, and technological developments. After the external factors are assessed, the internal strengths and weaknesses of the organization's incumbents must be identified. Factors to include in an internal assessment are current workforce skills, retirement patterns, demographic profiles, and employee capabilities.

The agency's vision, mission, and measurable goals and objectives drive the identification of future functional requirements, which in turn drive the analysis and elements of the workforce plan. The question to ask is, "What key functions need to be performed to move in the direction set out in the strategic plan?" This may include many current functions, in addition to forecasting important future functions and activities. This information can be used to forecast the organization's capabilities to confront its future opportunities and threats. The ultimate feasibility of strategic planning depends on the people who make it operational. Agency leaders need to understand how their workplaces will be affected by impending changes and prepare accordingly. A number of reports alert public managers to the need to become proactive and develop a strategic HR plan:

The Case for Transforming Public Sector Human Resources Management (National Academy of Public Administration, 2000) Federal Employee Retirements: Expected Increase Over the Next Five Years Illustrates Need for Workforce Planning (U.S. General Accounting Office, 2001a) Workforce Planning Resource Guide for Public Sector Human Resource Professionals (International Personnel Management Association for Human Resources, 2002) Human Capital: A Guide for Assessing Strategic Training and Development Efforts in the Federal Government (U.S. General Accounting Office, 2004b) Human Capital: Federal Workforce Challenges in the 21 st Century (U.S. General Accounting Office, 2007).

Journal of Business and Social Sciences (JBSS) 


\section{Strategic Human Resources Planning}

Human resources planning, a critical component of strategic planning and SHRM, is the process of analyzing and identifying the need for and availability of human resources to meet the organization's objectives. In an effort to be proactive, the U.S. Office of Personnel Management (2005) developed a five - step workforce planning model:

\section{Step 1: Strategic direction}

This involves linking the workforce planning process with the agency's strategic plan, annual performance and business plan, and work activities required to carry out long - and short - term goals and objectives.

Step 2: Analyze the workforce, identify skills gaps, and conduct workforce analysis

This involves determining what the current workforce resources are and how they will evolve through turnover; developing specifications for the kinds, numbers, and locations of workers and managers needed to accomplish the agency's strategic requirements; and determining what gaps exist between the current and projected workforce needs.

\section{Step 3: Develop an action plan}

This involves the identification of strategies to close gaps, plans to implement the strategies, and measures for assessing strategic progress. These strategies could include recruiting, training and retraining, restructuring organizations, contracting out, succession planning, and technological upgrades.

\section{Step 4: Implement the action plan}

This involves ensuring that human and fiscal resources are in place; roles are understood; and the necessary communication, marketing, and coordination are occurring to execute the plan and achieve the strategic objectives.

\section{Step 5: Monitor, evaluate, and revise}

This involves monitoring progress against milestones, assessing for continuous improvements, and adjusting the plan to make course corrections and address new issues.

\section{Implementing Strategic Human Resources Management}

HRM departments seeking to implement an SHRM system must expand their scope of activities beyond their traditional tasks and functions and enter partnerships with managers and employees. Working together provides managers and employees with a better understanding of HRM issues, and HRM staff becomes better informed about the needs of the employees and departments. SHRM is a process that must be implemented throughout the organization in such a way that it becomes the template for organizational change and innovation. The Partnership for Public Service (2006) has developed a process overview for federal executives, but its prescriptions apply to managers in all organizations: 


\section{Build a planning project team}

When assembling a planning team, include HR professionals as well as agency leaders. Agency leaders provide sponsorship for the planning process and strategic directions for the plan, while HR professionals bring other expertise. The process must be collaborative, and those charged with responsibility for the plan must be given the necessary time and resources. The planning project team should identify the approach taken, the tasks associated with implementing those tasks, and time frames in which to complete them. Accountability among team members is important.

\section{Review relevant inputs}

Once the planning team is in place, collect and analyze information about the workforce and review relevant documents. The team should also review agency and department strategic plans; existing human capital plans; retirement, attrition, and hiring projections; staffing and recruitment plans; external stakeholder issues and concerns; employee views; and other successful models of SHRM.

\section{Engage managers}

Senior managers should be engaged while developing the plan. There should be a cross - section of senior managers representing the full range of major functions. Managers typically are most aware of the challenges to a unit's mission and its workforce.

\section{Assess challenges and devise solutions}

The planning team should collaborate to identify challenges and develop solutions. Quantitative data about the workforce should be reviewed, including information about retirement, attrition, and hiring projections; staffing plans; and employee feedback. Qualitative information that should be considered includes information about strategic goals and priorities, the workforce needed to achieve those goals, and potential challenges to building or maintaining the workforce.

\section{Draft the plan}

Before writing the plan, prepare a comprehensive outline and solicit feedback from agency leaders and managers, employees, and external stakeholders. The plan should also set out a time line for action, the tactics to be used, and the tasks associated with each change initiative, time frames for completion, those responsible for each item, and the metrics for assessing success.

\section{Evaluating the Effectiveness of Strategic Human Resources Management}

To evaluate the effectiveness of SHRM, SHRM audits and HR benchmarking and return on investment analysis can be used.

\section{SHRM Audit}

One method used to assess SHRM effectiveness is an HRM audit, an in - depth analysis that evaluates the current state of SHRM in an organization. The audit identifies areas of strengths and weaknesses and where improvements are needed. During the 
audit, current practices, policies, and procedures are reviewed. Many audits also include benchmarking against organizations of similar size or industry. A number of areas are typically included in an audit: Legal compliance (Equal Employment Opportunity Act, Occupational Safety and Health Act, Fair Labor Standards Act, Employment Retirement Income Security Act, Family and Medical Leave Act, privacy) Current job descriptions and specifications Valid recruiting and selection procedures Compensation and pay equity and benefits Employee relations Absenteeism and turnover control measures Training and development activities Performance management systems Policies and procedures/ employee handbook Terminations Health, safety, and security issues.

\section{HR Benchmarking and Return on Investment}

Human resource management departments, like other units, are being asked to demonstrate their value to public and nonprofit organizations. Human resource audits and HRIS are being used with greater frequency to obtain information on HR performance. Once information on performance has been gathered, it must be compared to a standard. One method of assessing HR effectiveness is comparing specific measures of performance against data on those measures in other organizations known for their best practices. Employee costs in public and nonprofit organizations can be anywhere from 50 to 80 percent of expenses; therefore, measuring the return on investment (ROI) in human capital is necessary to show the impact and value of SHRM. According to Fitz-enz (2000, p. 3), "Management needs a system of metrics that describe and predict the cost and productivity curves of its workforce." Quantitative measures focus on cost, capacity, and time, whereas qualitative measures focus on more intangible values such as human reactions. ROI calculations are used to show the value of expenditures for HR activities. Human resource activities and programs that have been subject to measurement include training programs, diversity programs, wellness and fitness initiatives, safety and health programs, skill - based and knowledge - based compensation, performance improvement programs, education programs, organizational development initiatives, change initiatives, career development programs, recruiting systems, and technology implementation (Phillips \& Phillips, 2002). Despite the belief that only for - profit organizations can evaluate ROI programs, public and nonprofit agencies can use measures of performance such as productivity, quality, time improvements, and cost savings through efficiency enhancements as well as qualitative measures.

\section{Problems and Implications of Strategic Human Resources Management}

HRM often considered a secondary support function rather than a driver of an organization's future? A number of reasons may exist. There are also financial costs associated with SHRM. Some public organizations may be reluctant to spend additional resources on employees, fearing a backlash from its elected officials and citizens. In some instances, leaders may want a greater integration of the HRM function with organizational strategy but often do not understand just what that means. Human resources management professionals may not have the flexibility to initiate new programs or suggest new organizational structures. This is especially true when organizational change issues may challenge existing rules and regulations as well as embedded 
standard operating procedures. The Colorado Municipal League surveyed its members on succession planning and found that the respondents believed it was a critical issue and also a challenge (Reester \& Braaten, 2006). When asked how well their organization was handling succession planning for executive levels of leadership, 66 percent responded poor or fair. Six primary factors were identified in the inability to establish a quality succession planning program: Bigger priorities on the horizon every day.

Organizational streamlining has created a time - constrained atmosphere where there is little time to invest in professional development. Compensation and benefits are lagging and likely successors will seek the nonprofit or private sector. Based on these few examples, it appears that local governments understand the need for succession planning, but not all have the time, resources, or support to implement it. The Government Accountability Office identified the following reasons that SHRM planning often fails: Lack of on - going support and interest from leadership Succession planning is not seen as a priority Funding is not sufficient Recruitment and retention, particularly in critical management areas, is perceived to be sufficient to meet organizational needs Resistance from middle managers who already feel overburdened with other " initiatives " not central to their job responsibilities Employee suspicion toward unsure program goals, poor communication and organization is too small to sustain a full - scale program (Flynn, 2006). Another reason that SHRM is neglected is that often HRM professionals lack the capabilities and skills necessary to move HRM to a more proactive role.

To be strategic partners, HRM departments must possess high levels of professional and business knowledge. They need to establish links to others in the organization who are working to improve performance and be able to demonstrate on a continuing basis how HRM activities contribute to the success and effectiveness of the organization. Unfortunately, many HRM departments have spent their time ensuring compliance with rules and regulations, so they lack the skills and competencies to act as a strategic partner. Organizational change also requires higher levels of coordination across functions and departments, and employees and management must be committed to continuous improvement.

There must be greater interdepartmental cooperation. Trust and open communication across the organization will have to be developed. Organizations must encourage creativity and recognize such creativity through their reward systems. Change requires fairness, openness, and empowerment, but these may be contrary to an organization's existing culture and may require several incremental steps to achieve. Some employees may be reluctant to change. Over the years, they may have acquired proficiency in the performance of their jobs. Changing their routines and standards of performance, requiring them to learn new skills, or obliging them to work with unfamiliar persons may be unsettling. Employees unwilling or unable to make the transition may choose to resign; some may even attempt to sabotage new initiatives. Sometimes the political realities of public organizations undermine change. Often elected officials and appointed officials have a short - term perspective regarding how they want agencies to operate. Changes in 
policies and procedures take time to implement and are often not immediately apparent. Elected officials may also be predisposed to favor short - term budget considerations over long - term planning. In the public sector, support for top administrators may change quickly and often capriciously, and in the nonprofit sector, the board of directors may be reluctant to embrace change. To transform an organization requires chief executive and top administrative support, managerial accountability, fundamental changes in HRM practices, employee involvement, and changes in agency culture.

\section{Conclusion}

Strategic human resources management guides management in identifying and implementing the appropriate HR learning activities for resolving organizational problems or adapting to meet new opportunities. It determines the HR needs of the agency and ensures that qualified personnel are recruited and developed to meet organizational needs. Should there be a shift in demand for services; agencies must know whether there are potential employees with the requisite skills available to provide these services and whether the agency's finances can afford the costs associated with additional compensation and benefits.

Forecasting an agency's HR supply reveals the characteristics of its internal supply of labor; it also helps to assess the productivity of incumbent employees, implement succession planning and salary planning, and identify areas where external recruitment or training and development are necessary. Training and development are essential to the effective use of an organization's human resources and an integral part of its planning. Training is used to remedy immediate needs, while development is concerned with long term objectives and the ability to cope with change. Training and development should be viewed as a continuous process.

There will always be new employees, new positions, new problems, changes in technology, and changes in the external and internal environments that require a planned approach to training and development and its integration with other HRM functions. Training and development influence recruitment, selection, career planning, and the compatibility between agency goals and employee aspirations. Training and development programs must be integrated to complement the organization's mission and operations. Organizations should use employees wisely with respect to the strategic needs of the organization. Turnover, including retirements, must be anticipated and planned for.

Human resources management departments must track the skills of incumbent employees and keep skill inventories. Recruitment and training must be tied to the organization's mission. The availability and stability of financial support; the advancement of technological changes, legal regulations, and social and cultural changes; and the evolution of HR requirements must be considered when developing strategic plans. At one time, organizations hired employees to fit the characteristics of a particular job. Now it is important for organizations to select employees who fit the characteristics not only of the position but also of the organization. Human resources management professionals 
must serve as internal consultants, working with managers to assess HR needs. Together they must project the demand for services, develop new resources, and determine the appropriate reallocation of services. The SHRM process, once established, can be used to anticipate and prepare for major changes affecting the workplace.

Effective strategic human capital management approaches serve as the foundation of any serious HRM initiative. They must be at the center of efforts to transform the cultures of agencies so that they become results oriented and externally focused. To facilitate these changes, HRM personnel and department managers must acquire new competencies to be able to deliver HRM services and shift toward a more consultative role for HR staff.

Like service industries and new economy companies, public and nonprofit organizations are driven by the knowledge and skills their employees possess. It is short sighted for elected officials, board members, funders, executives, and other agency leaders to dismiss the importance of SHRM. As important, organizations must reinforce the importance of human capital and the contribution that knowledge management makes to the effective delivery of services. Human resource management departments must have the knowledge, skills, and authority to identify and facilitate changes.

\section{References}

Fitz-enz, J., (2002). The ROI of Human Performance: Measuring the Economic Value of Employee Performance. New York: AMACOM.

Flynn, J.P., (2006). Designing a Practical Succession Planning Program. PA Times, Vol. $4(6)$.

IPMA-HR, (2002). Workforce Planning Resource Guide for Public Sector Human Resource Professionals. Washington, DC: Author.

National Academy of Public Administration, (2000). The Case for Transforming Public Sector Human Resources Management. Washington, DC: Author.

Partnership for Public Service, (2006). Develop an Effective Strategic Human Capital Plan: A Process Overview for Federal Executives. Washington, DC: Author.

Phillips, P. P., \& Phillips, J. J. (2002). The Public Sector Challenge: Developing a Credible ROI Process. Measuring ROI in the Public Sector, pp. 1 - 32.

Reester, K., \& Braaten, M. (2006). Succession Planning Now Say Colorado Municipal Executives. PA Times, pp. $3-4$.

U.S. General Accounting Office, (2001). Federal Employee Retirements: Expected Increase Over the Next 5 years Illustrates Need for Workforce Planning. Washington, DC: U.S. Government Printing Office.

U.S. General Accounting Office, (2001). Securities and Exchange Commission: Human

Capital Challenges Require Management Attention. Washington, DC: U.S.

Government Printing Office.

U.S. General Accounting Office. (2004). Human Capital: Selected Agencies' Use of Alternative Service Delivery Options for Human Capital Activities.Washington, DC: Author. 
U.S. General Accounting Office. (2004). Human Capital: A Guide for Assessing Strategic Training and Development Efforts in the Federal Government. Washington, DC: Author.

U.S. Government Accountability Office. (2007). Human Capital: Efforts to Enhance Diversity and Ensure a Fair and Inclusive Workplace at GAO. Washington, DC: Author.

U.S. Government Accountability Office. (2007b). Human capital: Federal Workforce Challenges in the 21 st Century. Washington, DC: Author.

U.S. Office of Personnel Management, (2005). OPM's Workforce Planning Model. Retrieved from; http://www.opm.gov/hcaaf_resource_center/assets/Sa_tool4.pdf. 